\title{
Multisystem proteinopathy due to a homozygous p.Arg159His VCP mutation
}

\section{A tale of the unexpected}

Willem De Ridder, MD, Abdelkrim Azmi, PhD, Christoph S. Clemen, MD, Ludwig Eichinger, PhD, Andreas Hofmann, PhD, Rolf Schröder, MD, Katherine Johnson, PhD, Ana Töpf, PhD, Volker Straub, MD, PhD, Peter De Jonghe, MD, PhD, Stuart Maudsley, PhD, Jan L. De Bleecker, MD, PhD, and Jonathan Baets, MD, PhD Neurology ${ }^{\circledR}$ 2019;00:1-12. doi:10.1212/WNL.0000000000008763

\section{Abstract}

\section{Objective}

To assess the clinical, radiologic, myopathologic, and proteomic findings in a patient manifesting a multisystem proteinopathy due to a homozygous valosin-containing protein gene $(V C P)$ mutation previously reported to be pathogenic in the heterozygous state.

\section{Methods}

We studied a 36-year-old male index patient and his father, both presenting with progressive limb-girdle weakness. Muscle involvement was assessed by MRI and muscle biopsies. We performed whole-exome sequencing and Sanger sequencing for segregation analysis of the identified p.Arg159His VCP mutation. To dissect biological disease signatures, we applied state-of-the-art quantitative proteomics on muscle tissue of the index case, his father, 3 additional patients with VCP-related myopathy, and 3 control individuals.

\section{Results}

The index patient, homozygous for the known p.Arg159His mutation in VCP, manifested a typical VCP-related myopathy phenotype, although with a markedly high creatine kinase value and a relatively early disease onset, and Paget disease of bone. The father exhibited a myopathy phenotype and discrete parkinsonism, and multiple deceased family members on the maternal side of the pedigree displayed a dementia, parkinsonism, or myopathy phenotype. Bioinformatic analysis of quantitative proteomic data revealed the degenerative nature of the disease, with evidence suggesting selective failure of muscle regeneration and stress granule dyshomeostasis.

\section{Conclusion}

We report a patient showing a multisystem proteinopathy due to a homozygous VCP mutation. The patient manifests a severe phenotype, yet fundamental disease characteristics are preserved. Proteomic findings provide further insights into VCP-related pathomechanisms.

\author{
Correspondence \\ Dr. Baets \\ jonathan.baets@ \\ uantwerpen.be
}




\section{Glossary}

CK = creatine kinase; $\mathbf{D D R}=$ DNA damage response FDR $=$ false discovery rate; FDT $=$ frontotemporal dementia; $\mathbf{I B M}=$ inclusion body myopathy; MHC-I = major histocompatibility complex I; MS = mass spectrometer; MSP1 = multisystem proteinopathy 1; PDB = Paget disease of bone; sIBM = sporadic inclusion body myopathy; $V C P$ = valosin-containing protein gene.

Mutations in the valosin-containing protein gene $(V C P)$ are associated with a rare, dominantly inherited multisystem proteinopathy (MSP1), which presents with a high diversity of combinations of phenotypes, including inclusion body myopathy (IBM), early-onset Paget disease of bone (PDB), frontotemporal dementia (FTD), amyotrophic lateral sclerosis, and parkinsonism. ${ }^{1}$ At present, $>40$ different heterozygous missense mutations have been reported in VCP. Important intrafamilial and interfamilial phenotypic variability has been noted. ${ }^{1,2}$ Penetrance of the myopathy phenotype, PDB, and FTD is estimated at $90 \%, 50 \%$, and $30 \%$, respectively. ${ }^{3}$ Onset of muscle weakness occurs during adulthood at a mean age of $\approx 40$ to 45 years. ${ }^{3,4}$

Mutations cluster in the $\mathrm{N}$ and D1 domains of the VCP protein, which is involved in multiple cellular processes and has a critical role in proteostasis, at the intersection of the ubiquitin-proteasome system and autophagy. ${ }^{1,5} \mathrm{VCP}$ belongs to the AAA + ATPase family (ATPases associated with diverse cellular activities) and uses energy from ATP hydrolysis to segregate molecules from immobile cellular structures such as protein complexes or aggregates, membranes, and chromatin, in conjunction with a collection of cofactors and adaptors. ${ }^{6,7}$ The exact molecular mechanisms of VCP-related disease remain unknown, ${ }^{5}$ particularly with regard to the tissue-specific nature of the disorder and genotype-phenotype correlations.

Here, we present a patient with MSP1 harboring in homozygosity the $V C P$ p.Arg 159 His mutation, previously reported to be only pathogenic in the heterozygous state. ${ }^{8-13}$ Detailed study of this patient demonstrates that the key MSP1 phenotypic characteristics are preserved in case of homozygosity of this VCP mutation.

\section{Methods}

\section{Standard protocol approvals, registrations, and patient consents}

Ethics approval was granted by the relevant local ethics committees of the participating centers. All participants provided written informed consent before participation in the study.

\section{Patients and clinical evaluation}

The index patient (patient A) and his father (patient B) presented with unexplained limb-girdle muscular weakness and an elevated serum creatine kinase (CK) level. No other family members agreed to be clinically evaluated except for the mother of patient A. Nerve conduction studies and an EMG were performed. Muscle MRI was performed on a $1.5 \mathrm{~T}$ MRI platform at the Antwerp University Hospital. Cross sections at the shoulder, abdominal, pelvic, thigh, and calf levels were assessed on T1-weighted images to evaluate patterns of muscle involvement. Fatty replacement of muscle was graded according to the Mercuri scale. ${ }^{14}$ Pulmonary function was assessed by spirometry testing (forced vital capacity) and cardiac function by ECG and echocardiography. Bone scintigraphy was carried out, and bone turnover markers in blood (alkaline phosphatase) and urine (collagen crosslinks) were evaluated.

\section{Analysis of exome sequencing data}

A DNA sample of patient A was submitted to the MRC Centre for Neuromuscular Diseases Biobank (Newcastle University, UK). Samples were processed, and whole-exome sequencing was performed and analyzed by a targeted approach, as described previously. ${ }^{15}$ A candidate variant in VCP (reference sequence NM 007126) was validated by Sanger sequencing, and segregation analysis was performed with DNA samples of patient $\mathrm{A}$, his father (patient $\mathrm{B}$ ), and his mother.

\section{Muscle biopsies}

Muscle biopsies of quadriceps muscle were obtained from patients $\mathrm{A}$ and $\mathrm{B}, 3$ additional patients with a $V C P$-related myopathy phenotype, and 3 control individuals (patients $\mathrm{C}-\mathrm{E}$ and controls $1-3$, clinical details in table 1) and analyzed following standard histologic and immunohistochemical light microscopy and electron microscopy protocols.

Patients D and E harboring the p.Gly125Asp mutation are siblings. Segregation studies confirmed that the mutation was inherited from the affected father, who also showed a VCPrelated myopathy phenotype. For all of the patients, the choice to biopsy the quadriceps muscle was similarly based on clinical and radiologic selective but not yet end-stage involvement of the muscle. Control individuals, biopsied for subjective myalgia but for whom no clinical, morphologic, or electrodiagnostic abnormalities had been identified, were selected on the basis of biopsied muscle, sex, and age.

\section{Sample preparation for iTRAQ labeling and MS analysis}

Proteins were extracted from muscle biopsy specimens of patients $\mathrm{A}$ through $\mathrm{E}$ and 3 control individuals in a buffer containing $4 \%$ sodium dodecyl sulfate, $100 \mathrm{mmol} / \mathrm{L}$ tris-2carboxyethyl phosphine, and $50 \mathrm{mmol} / \mathrm{L}$ Tris, $\mathrm{pH}$ 7.8. Lysates were heated at $95^{\circ} \mathrm{C}$ for 5 minutes. The extracted proteins were precipitated with trichloroacetic acid and resolubilized in $8 \mathrm{~mol} / \mathrm{L}$ urea, $2 \mathrm{~mol} / \mathrm{L}$ thiourea, and $0.1 \%$ sodium dodecyl sulfate in $50 \mathrm{mmol} / \mathrm{L}$ triethylammonium bicarbonate. After measurement of protein concentrations with the RCDC kit (Bio- 
Table 1 Characteristics of 5 patients with a VCP-related myopathy phenotype and 3 control individuals

\begin{tabular}{|c|c|c|c|c|c|}
\hline & Patient A & Patient B & Patient C & Patient D & Patient E \\
\hline Sex & Male & Male & Male & Male & Female \\
\hline AAO, y & 29 & 58 & 53 & 58 & 58 \\
\hline $\begin{array}{l}V C P \\
\text { mutation }\end{array}$ & $\begin{array}{l}\text { p.Arg159His } \\
\text { (homozygous) }\end{array}$ & p.Arg159His & p.Arg159His & p.Gly125Asp & p.Gly125Asp \\
\hline $\begin{array}{l}\text { Presenting } \\
\text { symptoms }\end{array}$ & Proximal weakness LL & $\begin{array}{l}\text { Proximal } \\
\text { weakness LL }\end{array}$ & Proximal weakness LL & Proximal weakness LL & Proximal weakness LL \\
\hline $\begin{array}{l}\text { Biopsy } \\
\text { (age, y) }\end{array}$ & $\begin{array}{l}\text { Myopathic, rimmed } \\
\text { vacuoles, endomysial } \\
\text { infiltrates (31) }\end{array}$ & $\begin{array}{l}\text { Myopathic, } \\
\text { rimmed } \\
\text { vacuoles (64) }\end{array}$ & $\begin{array}{l}\text { Myopathic, rimmed } \\
\text { vacuoles, endomysial } \\
\text { infiltrates (57) }\end{array}$ & $\begin{array}{l}\text { Myopathic, endomysial } \\
\text { infiltrates, with invasion of } \\
\text { nonnecrotic muscle fibers (58) }\end{array}$ & $\begin{array}{l}\text { Myopathic, endomysial } \\
\text { infiltrates, with invasion of } \\
\text { nonnecrotic muscle fibers (59) }\end{array}$ \\
\hline $\begin{array}{l}\text { Biopsied } \\
\text { muscle }\end{array}$ & Quadriceps & Quadriceps & Quadriceps & Quadriceps & Quadriceps \\
\hline Control & & \multicolumn{2}{|c|}{ Control 1} & Control 2 & Control 3 \\
\hline Sex & & \multicolumn{2}{|c|}{ Male } & Male & Male \\
\hline \multicolumn{2}{|c|}{ Age at present, $y$} & \multicolumn{2}{|l|}{58} & 66 & 63 \\
\hline \multicolumn{2}{|c|}{ Age at biopsy, y } & \multicolumn{2}{|l|}{53} & 58 & 59 \\
\hline \multicolumn{2}{|c|}{ Biopsied muscle } & \multicolumn{2}{|c|}{ Quadriceps } & Quadriceps & Quadriceps \\
\hline
\end{tabular}

Abbreviations: $A A O=$ age at onset; $L L=$ lower limbs; $V C P=$ valosin-containing protein gene.

Rad, Hercules, CA), equal amounts of proteins from each lysate were reduced and alkylated with tris-2-carboxyethyl phosphine and 5-methyl-methanoethiosulphate, respectively, followed by trypsin digestion. Peptides from each sample were labeled with iTRAQ reagents 8plex (Sciex, Concord, Ontario, Canada) according to the manufacturer's instructions. The mixed peptides were separated on an offline 2D liquid chromatography system (Dionex, ULTIMATE 3000; ThermoScientific, Waltham, MA), consisting of a $15-\mathrm{cm}$ strong cationic exchange column and a $25-\mathrm{cm}$ nano-RP C18 column. The nanoliquid chromatography was coupled online to a QExactive-Plus Orbitrap (ThermoScientific) mass spectrometer (MS).

\section{Bioinformatic analysis of MS data}

The generated raw data from the MS were processed with the Proteome Discoverer 2.1 (PD2.1) software (ThermoScientific). For protein identification, the search engine Sequest HT was used against the human UniProt/SwissProt database with a false discovery rate (FDR) of $<1 \%$. The quantitative proteomics data were then further statistically analyzed with the Perseus software (version 1.6.1.1). ${ }^{16} \log _{2^{-}}$ transformed scaled abundance values generated by the PD2.1 software were normalized by subtraction of the median value of the respective column. The complete list of identified proteins with the original scaled abundance values is available from Dryad (table e-1, doi.org/10.5061/dryad. 60fn581). Hierarchical clustering analyses were performed with euclidean algorithms. Volcano plot analyses assessing statistical significance ( $t$ test) together with fold change $(F D R=0.05, S 0=0.1)$ were performed to identify significantly dysregulated proteins between patients and controls.
The downstream canonical pathways analysis (filtering based on $p$ value of overlap) and the upstream regulator analysis (filtering based on $\mid z$ score $\mid \geq 2$ ) as a causal analysis approach were applied on this set of dysregulated proteins, using the Ingenuity Pathway Analysis software (Qiagen, Venlo, the Netherlands). ${ }^{17}$ To identify significant outlier values in the data of the index patient compared to the other patients, a Significance A analysis in Perseus was performed ${ }^{18}$ correcting for multiple hypothesis testing with the Benjamini-Hochberg FDR (FDR $=0.05)$.

\section{Immunoblotting}

Protein extractions of muscle tissue specimens from patients A through $\mathrm{C}$ and a pooled extract of the control individuals used for MS analysis were subjected to Western blotting to validate the MS dataset. Equal amounts of protein were loaded and separated on $4 \%$ to $12 \%$ NuPAGE Bis-Tris gels (Life Technologies, Carlsbad, CA) and transferred onto a polyvinylidene difluoride membrane (Hybond P; Amersham Biosciences, Little Chalfont, UK). Membranes were probed with the following selective primary antibodies: anti-PGAM2 (ab97800; Abcam, Cambridge, UK), anti-LMNB1 (LS-B11184; LSBio, Seattle, WA), anti-MFF (ab81127; Abcam), anti-GAPDH (GTX100118; GeneTex, Irvine, CA), and anti-VCP (ab11433, Abcam and No. 2648; Cell Signaling Technology, Danvers, MA). Immunodetection was performed using host-specific secondary antibodies conjugated with horseradish peroxidase and the ECL-plus chemiluminescent detection system (ThermoScientific). Western blot results were visualized with the Amersham Imager 600 digital imaging system and quantified with ImageQuant TL software (GE Healthcare Life Sciences, 
Marlborough, MA). Quantitative data were normalized to GAPDH expression levels. Expression data were visualized as ratios of the respective sample relative to the pooled controls and compared to $\log _{2}$ iTRAQ expression ratios.

\section{Data availability}

Anonymized data not published within the article will be shared on request by any qualified investigator.

\section{Results}

\section{Genetic findings}

A rare variant in $V C P$ was identified in the exome of patient A. He appeared to harbor the previously reported heterozygous pathogenic p.Arg159His (c.476 G>A) mutation in homozygosity. ${ }^{8-13}$ DNA of the parents was available for segregation analysis; both were confirmed to be heterozygous carriers of the mutation (figure 1).

\section{Clinical aspects}

Patient A, a 36-year-old man of Belgian ancestry, presented with complaints related to progressive proximal weakness in the lower limbs that started at the age of 29 years. Clinically, marked atrophy of lower limb muscles was noted. Nerve conduction studies yielded normal results; an EMG showed a mixed pattern of neurogenic or myogenic discharges. Similarly, a diagnostic muscle biopsy performed at that time appeared to show a mixed pattern of myopathic and apparently neurogenic abnormalities. Weakness in the limbs progressed to distal weakness in the lower limbs with a marked foot drop bilaterally and upper limb, periscapular, and paraspinal weakness. The patient was re-evaluated in our center at the age of 31 years. DNA was sent for whole-exome sequencing, and the muscle biopsy was reassessed. MRI revealed an asymmetric pattern of patchy muscle involvement with preferential involvement of paraspinal and lower limb muscles (figure 2).

At the age of 63 years, patient B (the father) presented with complaints related to proximal weakness in the lower limbs, with symptoms slowly progressing since the age of 58 years. MRI studies revealed a patchy pattern of muscle involvement similar to that observed in patient A (figure 2). During followup, the patient noticed an impairment of his right hand function, which could clinically be attributed to an asymmetric extrapyramidal syndrome.

The serum CK level for patient B was only mildly elevated (192 U/L), contrasting with the high CK level for patient A (1138 U/L). Clinical details for patient A and B are summarized in table 2 , and a detailed description of the pattern of muscle weakness is available from Dryad (table e-2, doi.org/ $10.5061 /$ dryad.60fn581).

On the maternal side of the family tree (figure 1), the maternal grandfather had exhibited a myopathy phenotype, and many individuals had been diagnosed with a dementia phenotype or parkinsonism in the past. Clinical examination of the mother at the age of 60 years showed no signs of a neuromuscular disorder, parkinsonism, dementia, or PDB. She refused additional technical investigations. In a detailed study of the

Figure 1 Segregation analysis of the $V C P$ p.Arg159His (c.476 G>A) mutation

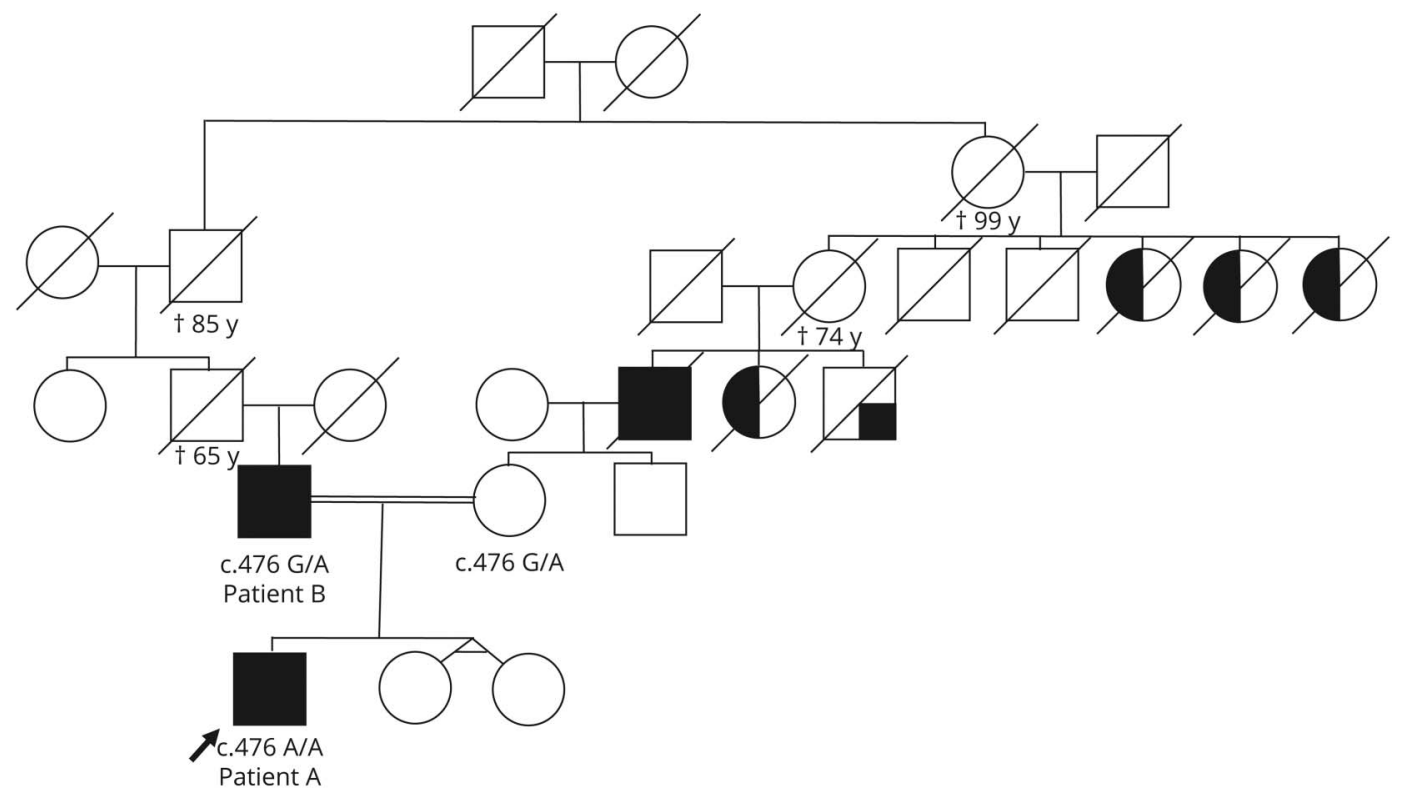

Only patient A and his parents were clinically examined. Segregation analysis confirmed that both parents were heterozygous carriers of the mutation. The maternal grandfather of patient A would have shown a myopathy phenotype and died at the age of 72 years. Arrow indicates index patient. Half-filled symbols represent individuals diagnosed with a dementia phenotype in the past; quarter-filled symbol represents an individual diagnosed with parkinsonism. $V C P=$ valosin-containing protein gene. †For the presumably asymptomatic obligatory carriers, the age at death (years) is mentioned. 
Figure 2 Muscle MRI findings for patients A and B

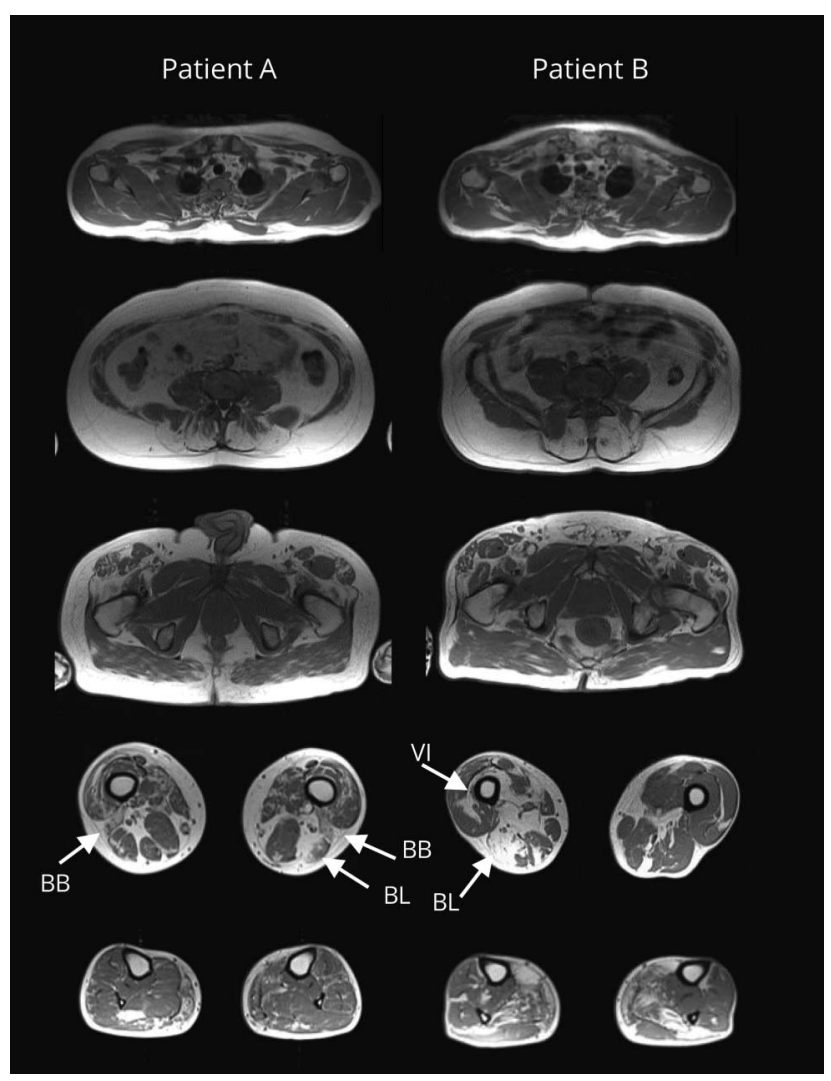

Axial T1-weighted images are shown for patients A and B (from top down: shoulder, abdominal, pelvic, thigh, and calf levels). Muscle groups at shoulder and pelvic levels were relatively spared on imaging. At thigh level, a patchy, asymmetric pattern of muscle involvement was noted of both quadriceps and muscle groups of the posterior compartment. Note the endstage involvement of biceps femoris caput brevis muscles (BB) in patient $A$ and asymmetric involvement of biceps femoris caput longus muscles (BL) in patients A and B. At calf level, selective involvement was observed of gastrocnemius and soleus muscles. VI = vastus intermedius muscle.

family history, there appeared to be distant consanguinity between the parents of the index patient (figure 1).

After identification of the VCP p.Arg159His mutation, bone scintigraphy and baseline studies of bone metabolism led to the diagnosis of an asymptomatic PDB lesion of vertebra L2 and the ilium on the right side for patient $A$. For patient $B$, the urinary pyridoline/creatinine ratio was borderline increased; a bone scintigraphy yielded normal results (table 2 ).

\section{Muscle biopsies}

Muscle biopsy of patient A (figure 3, A-D) showed myopathic features, with increased fiber size variation and multiple internalized nuclei but also apparently neurogenic features demonstrated by the presence of angular atrophic fibers. There was no evident fiber-type grouping or grouped atrophy. Scattered necrotic and regenerating fibers and fibers with rimmed vacuoles and endomysial inflammatory infiltrates were present. Immunostainings demonstrated that inflammatory infiltrates consisted mainly of CD68+ macrophages (figure 3C). Major histocompatibility complex I
(MHC-I) was regionally upregulated at the sarcolemma (figure 3D). Electron microscopy analysis revealed 15- to 18$\mathrm{nm}$ tubulofilamentous inclusions and rimmed vacuoles.

On the muscle biopsy of patient B, myopathic features consisting of an increased percentage of internalized nuclei and an increased fiber size variation were also noted. A few rimmed vacuoles were visualized; however, no striking signs of necrosis or regeneration were noted. Ultrastructural analysis confirmed nonspecific myopathic features.

Muscle biopsies of patients $\mathrm{C}$ through $\mathrm{E}$ similarly revealed mainly myopathic features (table 1), with some scattered angular atrophic fibers and endomysial inflammatory infiltrates with focal invasion of nonnecrotic muscle fibers (figure e-1 available from Dryad, doi.org/10.5061/dryad.60fn581). Muscle biopsy studies of the control individuals yielded strictly normal results (table 1).

\section{Proteomic investigation and bioinformatic interpretation of $V C P$-related disease signatures in skeletal muscle}

To investigate VCP-related myopathy pathomechanisms in more detail, an exploratory comparative proteomic study was performed on skeletal muscle tissue lysates of patients $A$ and $B$, 3 additional patients (patients $\mathrm{C}-\mathrm{E}$ ) with a VCP-related myopathy phenotype, and 3 control individuals. In total, 1,656 iTRAQ-labeled proteins were detected across the 8 samples. When the dataset was visualized by means of hierarchic clustering, patient $\mathrm{A}$ appeared to cluster most closely with patient $\mathrm{E}$ (figure 4A). To create a general appreciation of $V C P$-related disease signatures in VCP-related myopathy muscle first, a volcano plot was generated to compare protein expression data of the 4 patients harboring a heterozygous mutation in VCP and the 3 control individuals, followed by functional annotation of significantly dysregulated proteins. According to the volcano plot analysis, 390 proteins were significantly dysregulated, of which 207 were downregulated, in patients compared to control individuals (figure 4B). A full list of these proteins is available from Dryad (table e-3, doi.org/10.5061/ dryad.60fn581). On the basis of the $p$ value of overlap, the top 10 enriched pathways identified in the canonical pathway analysis reflected mainly downstream consequences of disease mechanisms, as evident by changes in metabolic pathways in muscle tissue of patients with a VCP-related myopathy (table 3, top). The pathway with the lowest (negative) $z$ score (predicted to be inhibited) was oxidative phosphorylation, and the one with the highest $z$ score (predicted to be activated) was sirtuin signaling pathway. The set of predicted potential key regulators, generated with the Ingenuity Pathway Analysis upstream regulator analysis, yielded additional pathomechanistic insights (full list available from Dryad, table e-4, doi.org/ $10.5061 /$ dryad.60fn581). Here, the predicted activation or inhibition of multiple upstream regulators (e.g., TWIST1, mir-1, MEF2C) reflected inhibition of myogenesis. Furthermore, inflammatory signatures were evident from the analysis, with multiple cytokines being predicted to be activated, as well as 
Table 2 Clinical characteristics of patients A and B

\begin{tabular}{|c|c|c|}
\hline & Patient A & Patient B \\
\hline Sex & Male & Male \\
\hline Age at present, $y$ & 36 & 66 \\
\hline AAO, y & 29 & 58 \\
\hline Presenting symptoms & Proximal weakness LL & Proximal weakness LL \\
\hline Maximal motor capability & Walking 300 m & Walking $25 \mathrm{~m}$ \\
\hline Walking aids & None & None \\
\hline Stairs & Cannot climb stairs since age $33 \mathrm{y}$ & Cannot climb stairs since age 65 y \\
\hline Marked muscle cramping & Yes & No \\
\hline Cardiac symptoms & No & No \\
\hline Age at last examination, y & 35 & 64 \\
\hline \multicolumn{3}{|l|}{ Weakness } \\
\hline \multicolumn{3}{|l|}{ Proximal } \\
\hline UL & Yes & No \\
\hline LL & Yes & Yes \\
\hline \multicolumn{3}{|l|}{ Distal } \\
\hline UL & Yes & No \\
\hline LL & Yes & Yes \\
\hline Other & Periscapular, paraspinal, abdominal muscles & Paraspinal \\
\hline Skeletal muscle atrophy & $\mathrm{LL}$, distal and proximal muscle groups & Quadriceps, forearms \\
\hline Scapular winging & Yes, marked & No \\
\hline Fasciculations & No & No \\
\hline Reflexes & Absent in UL, normal PTR, absent ATR & Absent in LL and UL \\
\hline Pyramidal tract signs & No & No \\
\hline Extrapyramidal signs & No & $\begin{array}{l}\text { Mild bradykinesia, rigidity, and } \\
\text { tremor of the right arm }\end{array}$ \\
\hline MoCA score & $28 / 30$ & $27 / 30$ \\
\hline Serum CK, U/L & 1,138 & 192 \\
\hline EMG (age, y) & $\begin{array}{l}\text { Mixed myopathic/neurogenic features; spontaneous } \\
\text { activity with positive sharp waves ( } 30 \text { ) }\end{array}$ & $\begin{array}{l}\text { Myopathic features; no } \\
\text { spontaneous activity (63) }\end{array}$ \\
\hline Resting ECG & Normal & Normal \\
\hline Echocardiography & Normal & Mild left ventricular hypertrophy \\
\hline Holter monitoring & Normal & Normal \\
\hline FVC, \% predicted & 81 & 74 \\
\hline Bone scintigraphy & Paget lesion of L2 and right ileum & Normal \\
\hline $\begin{array}{l}\text { Urinary pyridoline/creatinine (normal values } \\
5.5-69.4 \mathrm{pmol} / \mu \mathrm{mol}), \mathrm{pmol} / \mu \mathrm{mol}\end{array}$ & 170 & 51 \\
\hline $\begin{array}{l}\text { Urinary deoxypyridoline/creatinine (normal values } \\
1.0-16.9 \mathrm{pmol} / \mu \mathrm{mol}), \mathrm{pmol} / \mu \mathrm{mol}\end{array}$ & 33.2 & 11.5 \\
\hline
\end{tabular}

Abbreviations: $\mathrm{AAO}=$ age at onset; $\mathrm{ATR}=$ Achilles tendon reflex; $\mathrm{CK}=$ creatine kinase; $\mathrm{FVC}=$ forced vital capacity; $\mathrm{LL}=$ lower limbs; $\mathrm{MoCA}=\mathrm{Montreal} \mathrm{Cognitive}$ Assessment; PTR = patellar tendon reflex; UL = upper limbs. 


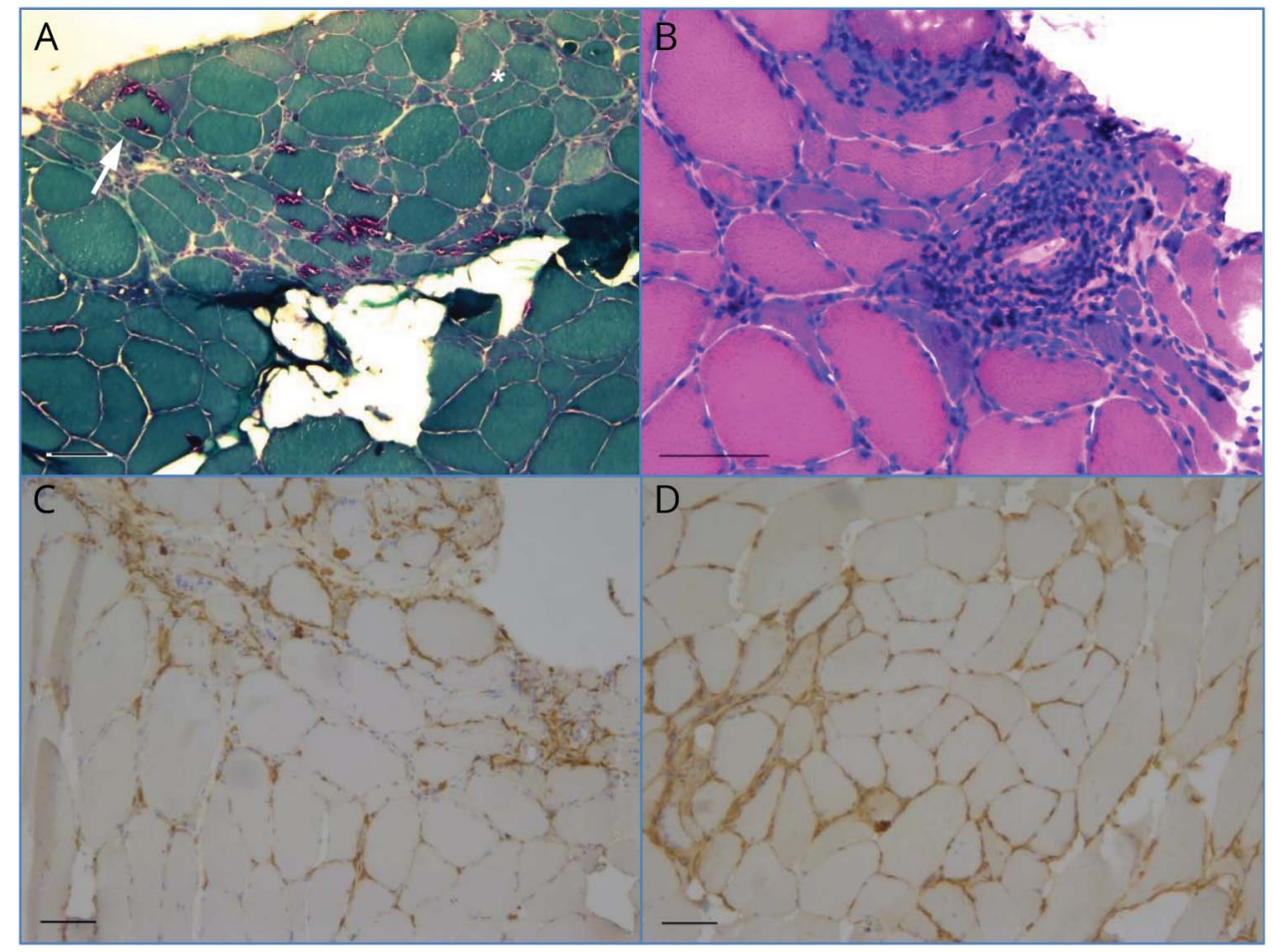

(A) Gomori trichrome staining showing rimmed vacuoles (arrow) in multiple fibers and a marked fiber size variation with atrophic fibers frequently being angularly shaped (asterisk). (B) Hematoxylin \& eosin staining showing $(C)$ an endomysial inflammatory infiltrate consisting mainly of CD68+ macrophages. (D) Regional upregulation of major histocompatibility complex I (MHC-I) immunoreactivity at the sarcolemma, also with histologically normal-appearing muscle fibers showing MHC-I upregulation. Scale bar $=100 \mu \mathrm{m}$.

dysregulation of a key metabolic regulator, PPARGC1A. The occurrence of oxidative stress in patient tissue was suggested by the predicted activation of NFE2L2, the key mediator the Nrf2mediated oxidative stress response, occurrence of endoplasmic reticulum stress, and the unfolded protein response by the predicted activation of XBP1. The upstream regulator with the highest positive $z$ score was KDM5A, a histone demethylase involved in the DNA damage response (DDR). ${ }^{19}$

Subsequently, a Significance A outlier analysis was performed in Perseus to search for differences between the proteomes of patient $\mathrm{A}$ and the heterozygous patients with $V C P$. This yielded a short list of 19 proteins that appeared to show significant outlier values (table 3, bottom) for patient A. The top hit was ZFAND1, a protein involved in the regulation of cytoplasmic stress granule turnover. Notably, RAD17 is a protein involved in the DDR, and WDR33 is an RNA-processing protein linked to mRNA homeostasis. Most of the other proteins, showing a less significant outlier value for the homozygous patient, represent proteins of the contractile apparatus in skeletal muscle.

Finally, we validated MS data of a discrete set of proteins, PGAM2, LMNB, and MMF, via Western blot analysis, with protein expression ratios between patients and pooled controls corroborating the data (figure 4, C and D). According to the MS dataset, protein expression levels of VCP were similar across patients and controls, which was also confirmed by Western blotting (figure e-2 available from Dryad, doi.org/10. 5061/dryad.60fn581).

\section{Discussion}

We report a patient with MSP1 harboring the p.Arg159His VCP mutation in homozygosity, previously reported to be pathogenic in heterozygous state. The index patient presented with young adult-onset proximal weakness in the lower limbs resulting after 6 years of evolution in walking distance restriction to $300 \mathrm{~m}$ and inability to climb stairs. In addition, distal weakness in upper and lower limbs, a marked bilateral foot drop, and scapular winging are typical clinical features of a VCPrelated myopathy. ${ }^{2}$ Furthermore, an asymptomatic PDB lesion was diagnosed. The father of the index patient, heterozygous for the p.Arg159His mutation, exhibited a myopathy phenotype with onset at 58 years of age and discrete asymmetric parkinsonism. The notion of a dementia or parkinsonism phenotype in multiple deceased family members and the observation that multiple obligatory carriers died presumably asymptomatic at an old age further illustrate the characteristic intrafamilial phenotypic variability of MSP1, even for the otherwise rather penetrant myopathy part of the disease spectrum. ${ }^{3}$

The p.Arg159His mutation has previously been reported to be pathogenic in the heterozygous state in multiple unrelated families showing intrafamilial and interfamilial phenotypic variability, encompassing IBM, PDB, FTD, and amyotrophic lateral sclerosis, which is typical for MSP1, without complete penetrance. ${ }^{8-13}$

Muscle MRI revealed an asymmetric and patchy pattern of muscle involvement in patients $A$ and $B$, with paraspinal and 
Figure 4 Visualization and validation of the quantitative proteomics data

A

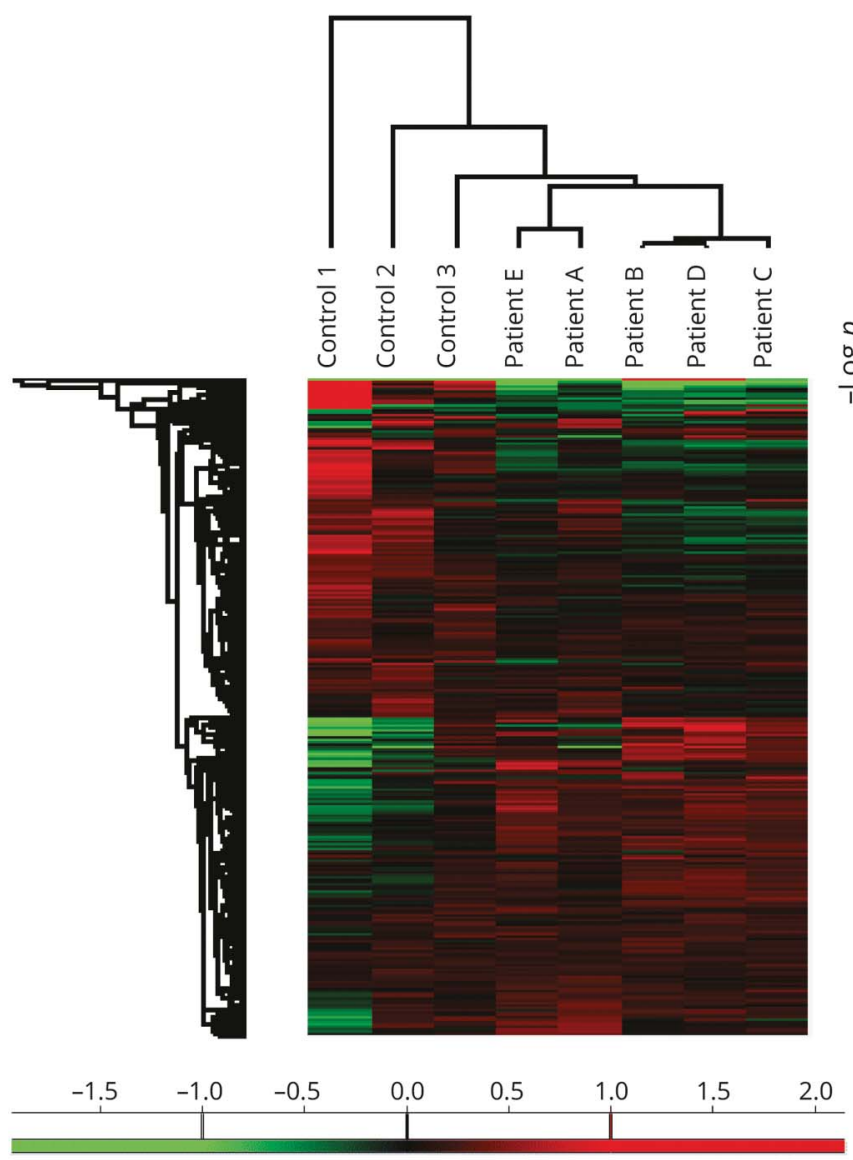

Intensity

C

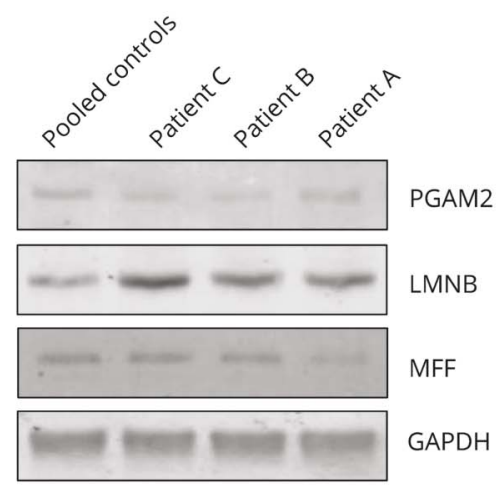

\section{B}

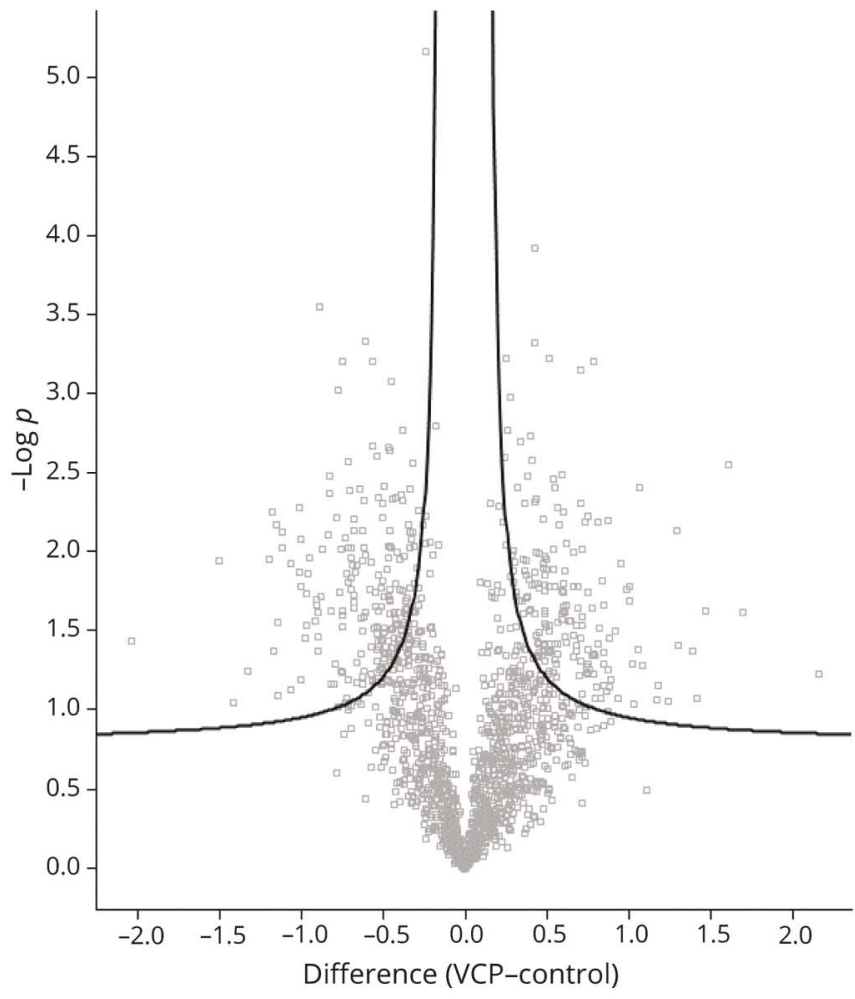

D

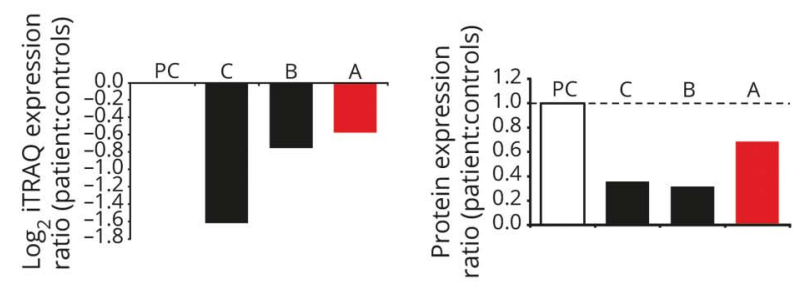

LMNB1
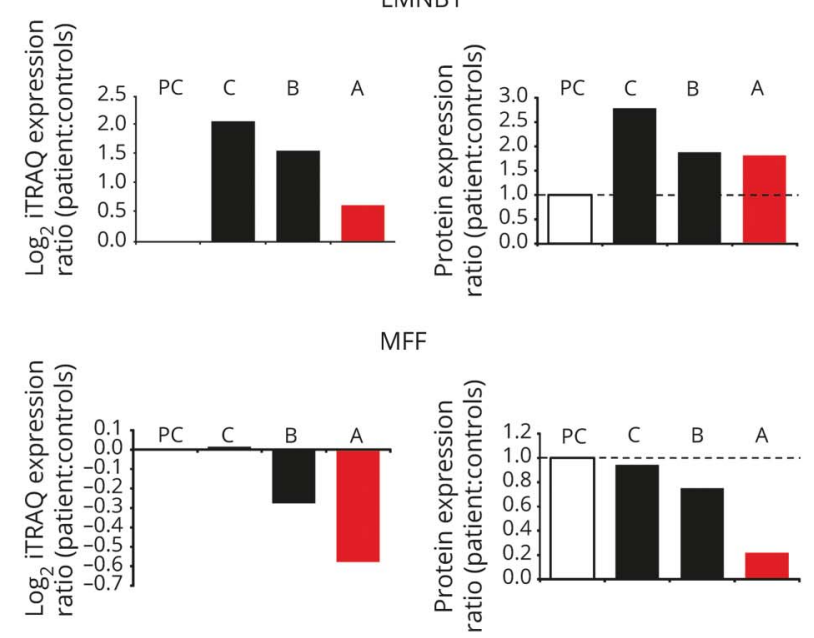

(A) Hierarchic clustering analysis (euclidean algorithms) based on the proteomic data of patients A through E and the 3 control individuals. Color codes of the intensities corresponding to the values that were normalized to the median across the complete dataset are shown below the heat maps. (B) Volcano plot analysis showing significantly dysregulated proteins (false discovery rate $=0.05, \mathrm{SO}=0.1$ ) between patients $\mathrm{B}$ through $\mathrm{E}$ and the 3 control individuals. Vertical axis corresponds to statistical significance $(-\log p)$; horizontal axis shows the average fold change between patients and control individuals (difference in log values). (C) Among upregulated or downregulated proteins, PGAM2, LMNB1, and MFF were validated with Western blot analysis. (D) Figures showing iTRAQ ratios on the left and protein expression data according to Western blot analysis on the right for PGAM2, LMNB1, and MFF. PC = pooled controls; VCP = valosincontaining protein gene. 
Table 3 Bioinformatic interpretation of the proteomics data

\begin{tabular}{|c|c|c|c|c|}
\hline \multicolumn{3}{|l|}{ Canonical pathways } & $p$ Value of overlap & $z$ Score \\
\hline \multicolumn{3}{|l|}{ Oxidative phosphorylation } & $3.981 \mathrm{E}-20$ & -4.491 \\
\hline \multicolumn{3}{|l|}{ Mitochondrial dysfunction } & $1.259 \mathrm{E}-19$ & $\mathrm{NaN}$ \\
\hline \multicolumn{3}{|l|}{ Sirtuin signaling pathway } & $6.310 \mathrm{E}-17$ & 3 \\
\hline \multicolumn{3}{|l|}{ Glycolysis I } & $3.981 \mathrm{E}-15$ & -3.464 \\
\hline \multicolumn{3}{|l|}{ Gluconeogenesis I } & $1.995 \mathrm{E}-13$ & -3.317 \\
\hline \multicolumn{3}{|c|}{ Epithelial adherens junction signaling } & $7.586 \mathrm{E}-10$ & $\mathrm{NaN}$ \\
\hline \multicolumn{3}{|l|}{ Calcium signaling } & $1.778 \mathrm{E}-08$ & 0 \\
\hline \multicolumn{3}{|l|}{ Actin cytoskeleton signaling } & $1.905 \mathrm{E}-08$ & 0.243 \\
\hline \multicolumn{3}{|c|}{ Remodeling of epithelial adherens junctions } & $2.344 \mathrm{E}-08$ & $\mathrm{NaN}$ \\
\hline \multicolumn{3}{|c|}{ Trichloroacetic acid cycle II (eukaryotic) } & $1.072 \mathrm{E}-07$ & -2.646 \\
\hline Significance A outlier analysis & $p$ Value & UniProt identifier & Protein name & \\
\hline ZFAND1 & $1.520 \mathrm{E}-14$ & Q8TCF1 & AN1-type zinc finger protein 1 & \\
\hline AK7 & $3.220 \mathrm{E}-10$ & Q96M32 & Adenylate kinase 7 & \\
\hline RAD17 & $3.220 \mathrm{E}-10$ & 075943 & DNA damage checkpoint control protein RAD17 & \\
\hline MYH4 & $6.220 \mathrm{E}-07$ & Q9Y623 & Myosin-4 & \\
\hline WDR33 & $1.310 \mathrm{E}-06$ & Q9C0j8 & Pre-mRNA 3' end processing protein WDR33 & \\
\hline IGHV3-72 & $5.240 \mathrm{E}-06$ & A0A087WW89 & Immunoglobulin heavy variable 3-72 & \\
\hline PLN & $6.800 \mathrm{E}-06$ & P26678 & Cardiac phospholamban & \\
\hline LRMP & $1.350 \mathrm{E}-05$ & Q12912 & Lymphoid-restricted membrane protein & \\
\hline MYLK & $5.960 \mathrm{E}-05$ & Q15746 & Myosin light chain kinase, smooth muscle & \\
\hline TNNC1 & $8.140 \mathrm{E}-05$ & P63316 & Troponin C, slow skeletal and cardiac muscles & \\
\hline HBB & $9.530 \mathrm{E}-05$ & P68871 & Hemoglobin subunit $\beta$ & \\
\hline ILF3 & $1.274 \mathrm{E}-04$ & Q12906 & Interleukin enhancer-binding factor 2 & \\
\hline HBA1 & $1.997 \mathrm{E}-04$ & P69905 & Hemoglobin subunit a & \\
\hline CRKL & $2.411 \mathrm{E}-04$ & P46109 & Crk-like protein & \\
\hline MYH1 & $2.769 \mathrm{E}-04$ & P12882 & Myosin-1 & \\
\hline STK10 & $2.899 \mathrm{E}-04$ & 094804 & Serine/threonine-protein kinase 10 & \\
\hline MYL2 & $3.432 \mathrm{E}-04$ & P10916 & MYL2 protein & \\
\hline TNNT1 & $4.847 \mathrm{E}-04$ & P13805 & Troponin T, slow skeletal muscle & \\
\hline NDST1 & $5.615 \mathrm{E}-04$ & P52848 & Bifunctional heparan sulfate $\mathrm{N}$-deacetyl & sferase 1 \\
\hline
\end{tabular}

Abbreviation: $\mathrm{NaN}=$ no activity pattern available.

Top: results of the Ingenuity Pathway Analysis canonical pathway analysis of proteins significantly dysregulated between the 4 patients harboring a heterozygous mutation in valosin-containing protein gene (VCP) (patients B-E) and 3 control individuals. Filtering based on $p$ value of overlap. Bottom: results of the Significance A outlier analysis in Perseus comparing protein expression data of patient A and patients harboring a heterozygous mutation in VCP (patients B-E).

lower limb muscles being preferentially involved. This patchy involvement has been described previously and seems to contrast with the selective patterns of muscle involvement in muscular dystrophies and sporadic IBM (sIBM), ${ }^{2,20,21}$

The muscle biopsy of patient A revealed myopathic features and the presence of atrophic angulated fibers, which are generally considered a neurogenic feature. However, no diagnosis of a lower motor neuron disease (disease of the anterior horn cell) or motor neuropathy (axonopathy) could be made from the clinical and electrophysiologic investigations. This mixture of myopathic and neurogenic features on muscle biopsy or on EMG appears to be frequent in VCP-related myopathies. This observation might suggest the occurrence of a subclinical 
mild motor axonopathy. ${ }^{13,22}$ Rimmed vacuoles, as observed in $\approx 35 \%$ to $0 \%$ of patients exhibiting a VCP-related myopathy phenotype, have an appearance similar to that of other rimmed vacuolar myopathies such as sIBM. ${ }^{2}$ The 15 - to 18 -nm tubulofilamentous inclusions, which were observed in muscle of patient A, have previously been observed in muscle of patients with VCP and are typically also observed in sIBM. ${ }^{13,23}$ The appearance of inflammatory infiltrates and MHC-I upregulation, as observed for patient A, might further complicate the histopathologic differential diagnosis with sIBM. ${ }^{23}$ On muscle biopsies of patients $\mathrm{C}$ through E, some endomysial inflammatory infiltrates were also observed, with focal invasion of nonnecrotic fibers on muscle biopsies of patients $\mathrm{D}$ and $\mathrm{E}$, but a systematic immunohistochemical study of inflammatory features could not be performed within the scope of this study. According to the literature, the appearance of inflammatory changes on muscle biopsies of patients manifesting a $V C P$-related myopathy seems to be rare or at least not conspicuous, although it has previously been mentioned briefly that some biopsies may show MHC-I upregulation or small inflammatory infiltrates. ${ }^{2}$ Focal invasion of nonnecrotic muscle fibers is typically observed in sIBM and appears to be a very rare phenomenon in inherited muscle disorders. ${ }^{24}$

Homozygous mutations in hereditary autosomal-dominant disorders are uncommon events. Generally, phenotypes are expected to be more pronounced, but systematic literature is evidently scarce. ${ }^{25}$ In case of a direct loss-of-function mechanism of the mutation leading to haploinsufficiency in the heterozygous state, a much more severe phenotype is anticipated. Dominant-negative mutations, however, are not expected to cause a much more severe phenotype, and for mutations exhibiting a gain of function, consequences seem to be variable. $^{25}$ In the present case, the index patient exhibited a typical pattern of muscle weakness. Yet, the onset age of the myopathy phenotype is rather early for this age-related disorder compared to patients harboring the same p.Arg159His mutation and indeed the complete group of patients with MSP1; the mean age at onset is $\approx 40$ to 45 years, with few patients being in their 20s. ${ }^{2,3,8-12,26}$ Notably, CK levels for the index patient are markedly elevated (1138 U/L), contrasting with CK levels generally reported to be normal or mildly elevated in VCP-related myopathies. ${ }^{3,4}$ Besides these anomalies, the 2 key features of VCP-related disease are preserved, i.e., the slowly progressive, age-related nature of the disorder and the tissue-specific phenotype. ${ }^{1}$ An example of another autosomal-dominant age-related disorder for which homozygosity of a known variant appeared to be viable and moderately accelerate the age at onset is familial Alzheimer disease linked to the E280A mutation in PSEN1. ${ }^{27}$ Other similar examples have been described in other protein aggregate myopathies, i.e., myotilinopathies and desminopathies. ${ }^{28,29}$

Because of the singularity of the observation of a human patient with a homozygous VCP mutation, we decided to dissect biological disease signatures by means of quantitative proteomic analyses. First of all, hierarchic clustering analyses did not yield arguments for globally different patterns of protein dysregulation at the level of the proteome between patient $\mathrm{A}$ and 4 other patients with a VCP-related myopathy or between patients harboring the p.Arg159His mutation or the p.Gly125Asp mutation. Functional annotation of proteins significantly dysregulated between heterozygous patients and control individuals yielded a general appreciation of VCP-related disease signatures in muscle. Whereas the downstream pathway analysis pointed mainly toward metabolic failure of skeletal muscle, the upstream regulator analysis reflected a broader landscape of potential pathomechanisms, including failure of muscle regeneration, oxidative stress, endoplasmic reticulum stress, and the unfolded protein response. Furthermore, the appearance of KDM5A as a predicted upstream regulator with the highest positive $z$ score also hinted at involvement of DDR signaling. ${ }^{19}$ Changes in cellular energy metabolism most likely represent a nonspecific downstream consequence of disease mechanisms in degenerative muscle disorders, as, for example, also described in a proteomic study of muscle tissue of patients manifesting a GNE-related myopathy. ${ }^{30}$ The focused outlier analysis conducted in the present study identified ZFAND1 as the top-scoring differentially regulated protein when the homozygous patient was compared with the heterozygous patients. This protein was recently identified as an evolutionarily conserved regulator of stress granule turnover that recruits VCP and the $26 \mathrm{~S}$ proteasome to organize degradation of stress granules. ${ }^{31}$ That ZFAND1 appears to be upregulated in muscle tissue of the homozygous patient compared to the heterozygous patients most likely indicates a compensatory mechanism, e.g., because of a more pronounced loss of interaction with VCP or a marked aggregation of stress granules. The relevance of stress granules for pathomechanisms of VCP-related disease had been suggested by the finding that $\mathrm{C} 2 \mathrm{C} 12$ myoblast cell lines transfected with mutant VCP showed delayed stress granule resolution on oxidative stress. ${ }^{32}$ Clinicopathologically, there are important similarities between VCPrelated disease and the multisystem proteinopathies related to mutations in stress granule components such as HNRNPA1 and HNRNPA2B1, further implicating a strong interconnection of proteostasis and stress granule homeostasis in disease. ${ }^{31,33}$

Structural appraisal of the p.Arg159His mutations using VCP $3 \mathrm{D}$ models ${ }^{34}$ supports the hypothesis that this mutation affects the interactor binding behavior of VCP only subtly. VCP is assembled as a homohexamer, with each monomer comprising an N-terminal domain and 2 ATPase domains (D1 and D2). The D1 and D2 domains are arranged in coaxially stacked rings, and the $\mathrm{N}$-terminal domains are located at the periphery of the ring formed by the D1 domains. ${ }^{1}$ Arg159 locates to the $\beta$-barrel moiety of the N-terminal domain of VCP, and its side chain is situated in the interface of the N-terminal domain and the D1 domain (residues 155-159, 386, 387). Of $>40$ reported disease mutations, 16 map to this interface. ${ }^{2}$ In general, amino acid residues located at domain interfaces of complex multidomain proteins are poised to engage in interdomain communications either through direct van der Waals or polar interactions or, more subtly, through allosteric mechanisms. Indeed, recent NMR-based studies investigating the conformational equilibrium of the N-terminal domain of VCP between the "up" (VCP: 
ATP) and "down" (VCP:ADP) states found that residues in this interface can cause subtle changes to the "up" or "down" equilibrium, which probably affects the binding behavior of VCP to its partner proteins. ${ }^{35,36}$ Visual inspection of the VCP hexamer from Protein Data Bank entry 1s3second ${ }^{34}$ indicates that the side chain of Arg 159 possibly engages in 2 interactions of importance, one with a residue in the same structural moiety (Glu124, $\beta$-barrel moiety of the $\mathrm{N}$-terminal domain) and one with a residue in the D1 domain (Ala232, RecA-like moiety). Replacing the side chain of 159 with an imidazolyl (histidine side chain) group would disrupt both interactions.

The clinical findings in this homozygous patient, together with the results of the proteomic analysis and a structural appraisal of the p.Arg159His mutation, suggest subtle changes of VCP dynamics and, as a result, altered binding behavior of $\mathrm{VCP}$ with respect to specific interactors as a likely (dominant-negative) molecular mechanism for the observed disease pathology. In particular, the present constellation allows the comparison of the proteomic consequences of the unique in vivo situation of having VCP hexamers constituting only mutant VCP monomers rather than a situation of having variable combinations of wild-type or mutant proteins in different VCP hexamers. Thus, the availability of homozygous and heterozygous patients presents a highly valuable resource because functional analysis of mutant VCP protein in vitro is always biased toward full mutant hexamers. ${ }^{7}$ However, with our current data, we cannot experimentally disprove the gain-of-function hypothesis that has recently been put forward ${ }^{5}$ based on the observation that the regulation of ATPase activity may be altered in VCP mutants. ${ }^{7}$ The ultimate set of upstream key regulators and key pathways that are specifically affected by the VCP p.Arg 159 His (or indeed any pathogenic) mutation remains to be unraveled.

Preservation of the age-related nature of the disorder in case of homozygosity of the $V C P$ p.Arg159His mutation contrasts with findings in the $V C P$ p.Arg155His homozygous missense mouse model, which exhibits growth retardation and early lethality (survival $<21$ days). ${ }^{37}$ Other animal models have been used for preclinical studies of compounds and to study the pathogenesis of VCP-related disease, of which the heterozygous VCP p.Arg155His+/- knock-in mouse model seems to mimic the MSP1 phenotype. ${ }^{38}$ However, because different missense mutations are being compared, these mouse models should be used with caution in the study of the molecular mechanisms of $V C P$ mutations especially considering the striking early-onset phenotype in the homozygous mice. Directly studying pathomechanisms in diseased tissue of patients is therefore highly relevant. This present study reports a proteomic dataset on muscle tissue of patients with VCP. Although this study focused on a relatively small yet relevant set of samples, it serves as a proof of concept for further investigations of molecular mechanisms of VCP pathologies.

Clearly, homozygosity of the p.Arg159His mutation in VCP appears to be viable, and key features of VCP-related disease are preserved. Notably, the observed phenotype appears to be slightly more severe than in patients harboring a heterozygous mutation in VCP. The findings in this study hint at the complex molecular mechanisms of VCP-related disease and illustrate the phenotypic variability and diagnostic pitfalls in MSP1.

\section{Acknowledgment}

The authors thank the patients and families for their cooperation and contributions.

\section{Study funding}

The study received financial support from Sanofi Genzyme, Ultragenyx, LGMD2I Research Fund, Samantha J Brazzo Foundation, LGMD2D Foundation, Kurt + Peter Foundation, Muscular Dystrophy UK, Coalition to Cure Calpain 3, and the "Association Belge contre les Maladies Neuromusculaires." S.M. is supported by the FWO-OP/Odysseus program (42/FA010100/32/6,484). J.B. is supported by a Senior Clinical Researcher mandate of the Research Fund-Flanders (FWO).

\section{Disclosure}

W. De Ridder, A. Azmi, C. Clemen, L. Eichinger, A. Hofmann, R. Schröder, K. Johnson, A. Töpf, V. Straub, P. De Jonghe, and S. Maudsley report no disclosures relevant to the manuscript. J. De Bleecker has served on the advisory boards of Sanofi Genzyme, Pfizer, and CSL Behring and has received travel funding or speaker honoraria of these companies. J. Baets reports no disclosures relevant to the manuscript. Go to Neurology.org/ $\mathrm{N}$ for full disclosures.

\section{Publication history}

Received by Neurology June 3, 2019. Accepted in final form August 28, 2019.

\section{Appendix Authors}

\begin{tabular}{|c|c|c|c|}
\hline Name & Location & Role & Contribution \\
\hline $\begin{array}{l}\text { Willem De } \\
\text { Ridder, MD }\end{array}$ & $\begin{array}{l}\text { University of } \\
\text { Antwerp, Belgium }\end{array}$ & Author & $\begin{array}{l}\text { Acquisition and } \\
\text { interpretation of patient, } \\
\text { imaging, histopathology, } \\
\text { and proteomic data, } \\
\text { analysis of genetic data, } \\
\text { manuscript writing }\end{array}$ \\
\hline
\end{tabular}

\begin{tabular}{|c|c|c|c|}
\hline $\begin{array}{l}\text { Abdelkrim } \\
\text { Azmi, PhD }\end{array}$ & $\begin{array}{l}\text { University of } \\
\text { Antwerp, Belgium }\end{array}$ & Author & $\begin{array}{l}\text { Acquisition and } \\
\text { interpretation of } \\
\text { proteomic data, critical } \\
\text { revision of the } \\
\text { manuscript for } \\
\text { important intellectual } \\
\text { content }\end{array}$ \\
\hline
\end{tabular}

\begin{tabular}{|c|c|c|c|}
\hline $\begin{array}{l}\text { Christoph } \\
\text { S. Clemen, } \\
\text { MD }\end{array}$ & $\begin{array}{l}\text { University Hospital } \\
\text { Cologne, Germany }\end{array}$ & Author & $\begin{array}{l}\text { Critical revision of the } \\
\text { manuscript for } \\
\text { important intellectual } \\
\text { content }\end{array}$ \\
\hline $\begin{array}{l}\text { Ludwig } \\
\text { Eichinger, } \\
\text { PhD }\end{array}$ & $\begin{array}{l}\text { University Hospital } \\
\text { Cologne, Germany }\end{array}$ & Author & $\begin{array}{l}\text { Critical revision of the } \\
\text { manuscript for } \\
\text { important intellectual } \\
\text { content }\end{array}$ \\
\hline
\end{tabular}

Continued 
Appendix (continued)

\begin{tabular}{|c|c|c|c|}
\hline Name & Location & Role & Contribution \\
\hline $\begin{array}{l}\text { Andreas } \\
\text { Hofmann, } \\
\text { PhD }\end{array}$ & $\begin{array}{l}\text { Griffith University, } \\
\text { Nathan, Brisbane, } \\
\text { Queensland, } \\
\text { Australia }\end{array}$ & Author & $\begin{array}{l}\text { Structural appraisal and } \\
\text { analyses, critical revision } \\
\text { of the manuscript for } \\
\text { important intellectual } \\
\text { content }\end{array}$ \\
\hline
\end{tabular}

\begin{tabular}{|c|c|c|c|}
\hline $\begin{array}{l}\text { Rolf } \\
\text { Schröder, } \\
\text { MD }\end{array}$ & $\begin{array}{l}\text { University Hospital } \\
\text { Erlangen, Germany }\end{array}$ & Author & $\begin{array}{l}\text { Critical revision of the } \\
\text { manuscript for } \\
\text { important intellectual } \\
\text { content }\end{array}$ \\
\hline
\end{tabular}

\begin{tabular}{|c|c|c|c|}
\hline $\begin{array}{l}\text { Katherine } \\
\text { Johnson, } \\
\text { PhD }\end{array}$ & $\begin{array}{l}\text { Newcastle } \\
\text { University, } \\
\text { Newcastle Upon } \\
\text { Tyne, UK }\end{array}$ & Author & Analysis of genetic data \\
\hline
\end{tabular}

\begin{tabular}{|c|c|c|c|}
\hline $\begin{array}{l}\text { Ana Töpf, } \\
\text { PhD }\end{array}$ & $\begin{array}{l}\text { Newcastle } \\
\text { University, } \\
\text { Newcastle Upon } \\
\text { Tyne, UK }\end{array}$ & Author & $\begin{array}{l}\text { Analysis of genetic data, } \\
\text { critical revision of the } \\
\text { manuscript for } \\
\text { important intellectual } \\
\text { content }\end{array}$ \\
\hline
\end{tabular}

\begin{tabular}{|c|c|c|c|}
\hline $\begin{array}{l}\text { Volker } \\
\text { Straub, } \\
\text { MD, PhD }\end{array}$ & $\begin{array}{l}\text { Newcastle } \\
\text { University, } \\
\text { Newcastle Upon } \\
\text { Tyne, UK }\end{array}$ & Author & $\begin{array}{l}\text { Critical revision of the } \\
\text { manuscript for } \\
\text { important intellectual } \\
\text { content }\end{array}$ \\
\hline $\begin{array}{l}\text { Peter De } \\
\text { Jonghe, } \\
\text { MD, PhD }\end{array}$ & $\begin{array}{l}\text { University of } \\
\text { Antwerp, Belgium }\end{array}$ & Author & $\begin{array}{l}\text { Acquisition of patient } \\
\text { data, critical revision of } \\
\text { the manuscript for } \\
\text { important intellectual } \\
\text { content }\end{array}$ \\
\hline
\end{tabular}

\begin{tabular}{|c|c|c|c|}
\hline $\begin{array}{l}\text { Stuart } \\
\text { Maudsley, } \\
\text { PhD }\end{array}$ & $\begin{array}{l}\text { University of } \\
\text { Antwerp, Belgium }\end{array}$ & Author & $\begin{array}{l}\text { Acquisition and } \\
\text { interpretation of } \\
\text { proteomic data }\end{array}$ \\
\hline $\begin{array}{l}\text { Jan L. De } \\
\text { Bleecker, } \\
\text { MD, PhD }\end{array}$ & $\begin{array}{l}\text { Ghent University } \\
\text { Hospital, Belgium }\end{array}$ & Author & $\begin{array}{l}\text { Acquisition and } \\
\text { interpretation of patient } \\
\text { and histopathology data, } \\
\text { critical revision of the } \\
\text { manuscript for } \\
\text { important intellectual } \\
\text { content }\end{array}$ \\
\hline
\end{tabular}

\begin{tabular}{|c|c|c|c|}
\hline $\begin{array}{l}\text { Jonathan } \\
\text { Baets, MD, } \\
\text { PhD }\end{array}$ & $\begin{array}{l}\text { University of } \\
\text { Antwerp, Belgium }\end{array}$ & Author & $\begin{array}{l}\text { Acquisition and } \\
\text { interpretation of patient, } \\
\text { imaging and } \\
\text { histopathology data, } \\
\text { study supervision, study } \\
\text { concept and design, } \\
\text { critical revision of the } \\
\text { manuscript for } \\
\text { important intellectual } \\
\text { content }\end{array}$ \\
\hline
\end{tabular}

\section{References}

1. Meyer $\mathrm{H}$, Weihl CC. The VCP/p97 system at a glance: connecting cellular function to disease pathogenesis. J Cell Sci 2014;127:3877-3883.

2. Evangelista T, Weihl CC, Kimonis V, Lochmuller H. 215th ENMC international workshop VCP-related multi-system proteinopathy (IBMPFD) 13-15 November 2015, Heemskerk, the Netherlands. Neuromuscul Disord 2016;26:535-547.

3. Mehta SG, Khare M, Ramani R, et al. Genotype-phenotype studies of VCP-associated inclusion body myopathy with Paget disease of bone and/or frontotemporal dementia. Clin Genet 2013;83:422-431.

4. Figueroa-Bonaparte S, Hudson J, Barresi R, et al. Mutational spectrum and phenotypic variability of VCP-related neurological disease in the UK. J Neurol Neurosurg Psychiatry 2016;87:680-681.

5. van den Boom J, Meyer H. VCP/p97-mediated unfolding as a principle in protein homeostasis and signaling. Mol Cell 2018;69:182-194.
6. Xia D, Tang WK, Ye Y. Structure and function of the AAA+ ATPase p97/Cdc48p. Gene 2016;583:64-77.

7. Ye Y, Tang WK, Zhang T, Xia D. A mighty "protein extractor" of the cell: structure and function of the p97/CDC48 ATPase. Front Mol Biosci 2017;4:39.

8. Haubenberger D, Bittner RE, Rauch-Shorny S, et al. Inclusion body myopathy and Paget disease is linked to a novel mutation in the VCP gene. Neurology 2005;65:1304-1305.

9. van der Zee J, Pirici D, Van Langenhove T, et al. Clinical heterogeneity in 3 unrelated families linked to VCP p Arg159His. Neurology 2009;73:626-632.

10. Koppers M, van Blitterswijk MM, Vlam L, et al. VCP mutations in familial and sporadic amyotrophic lateral sclerosis. Neurobiol Aging 2012;33:837.e837-813.

11. Papadimas GK, Paraskevas GP, Zambelis T, et al. The multifaceted clinical presentation of VCP-proteinopathy in a Greek family. Acta Myol 2017;36:203-206.

12. Segers K, Glibert G, Callebaut J, Kevers L, Alcan I, Dachy B. Involvement of peripheral and central nervous systems in a valosin-containing protein mutation. J Clin Neurol 2014;10:166-170.

13. Stojkovic T, Hammouda el H, Richard P, et al. Clinical outcome in 19 French and Spanish patients with valosin-containing protein myopathy associated with Paget's disease of bone and frontotemporal dementia. Neuromuscul Disord 2009;19:316-323.

14. Mercuri E, Pichiecchio A, Allsop J, Messina S, Pane M, Muntoni F. Muscle MRI in inherited neuromuscular disorders: past, present, and future. J Magn Reson Imaging 2007; $25: 433-440$

15. Johnson K, Topf A, Bertoli $\mathrm{M}$, et al. Identification of GAA variants through whole exome sequencing targeted to a cohort of 606 patients with unexplained limb-girdle muscle weakness. Orphanet J Rare Dis 2017;12:173.

16. Tyanova S, Temu T, Sinitcyn P, et al. The Perseus computational platform for comprehensive analysis of (prote)omics data. Nat Methods 2016;13:731-740.

17. Kramer A, Green J, Pollard J Jr, Tugendreich S. Causal analysis approaches in ingenuity pathway analysis. Bioinformatics 2014;30:523-530.

18. Cox J, Mann M. MaxQuant enables high peptide identification rates, individualized p.p.b.-range mass accuracies and proteome-wide protein quantification. Nat Biotechnol 2008;26:1367-1372.

19. Gong F, Clouaire T, Aguirrebengoa M, Legube G, Miller KM. Histone demethylase KDM5A regulates the ZMYND8-NuRD chromatin remodeler to promote DNA repair. J Cell Biol 2017;216:1959-1974.

20. Straub V, Carlier PG, Mercuri E. TREAT-NMD workshop: pattern recognition in genetic muscle diseases using muscle MRI: 25-26 February 2011, Rome, Italy. Neuromuscul Disord 2012;22(suppl 2):S42-S53.

21. Tasca G, Monforte M, De Fino C, Kley RA, Ricci E, Mirabella M. Magnetic resonance imaging pattern recognition in sporadic inclusion-body myositis. Muscle Nerve 2015;52:956-962.

22. Kazamel M, Sorenson EJ, McEvoy KM, et al. Clinical spectrum of valosin containing protein (VCP)-opathy. Muscle Nerve 2016;54:94-99.

23. Rose MR. ENMC international workshop: inclusion body myositis, 2-4 December 2011, Naarden, the Netherlands. Neuromuscul Disord 2013;23:1044-1055.

24. Ikenaga C, Kubota A, Kadoya M, et al. Clinicopathologic features of myositis patients with CD8-MHC-1 complex pathology. Neurology 2017;89:1060-1068.

25. Zlotogora J. Dominance and homozygosity. Am J Med Genet 1997;68:412-416.

26. Al-Obeidi E, Al-Tahan S, Surampalli A, et al. Genotype-phenotype study in patients with valosin-containing protein mutations associated with multisystem proteinopathy. Clin Genet 2018;93:119-125.

27. Kosik KS, Munoz C, Lopez L, et al. Homozygosity of the autosomal dominant Alzheimer disease presenilin 1 E280A mutation. Neurology 2015;84:206-208.

28. Rudolf G, Suominen T, Penttila S, et al. Homozygosity of the dominant myotilin c.179C $>$ T (p.Ser60Phe) mutation causes a more severe and proximal muscular dystrophy. J Neuromuscul Dis 2016;3:275-281.

29. Durmus H, Ayhan O, Cirak S, et al. Neuromuscular endplate pathology in recessive desminopathies: lessons from man and mice. Neurology 2016;87:799-805.

30. Sela I, Milman Krentsis I, Shlomai Z, et al. The proteomic profile of hereditary inclusion body myopathy. PLoS One 2011;6:e16334

31. Turakhiya A, Meyer SR, Marincola G, et al. ZFAND1 recruits p97 and the $26 \mathrm{~S}$ proteasome to promote the clearance of arsenite-induced stress granules. Mol Cell 2018;70:906-919.e907.

32. Rodriguez-Ortiz CJ, Flores JC, Valenzuela JA, et al. The myoblast $\mathrm{C} 2 \mathrm{C} 12$ transfected with mutant valosin-containing protein exhibits delayed stress granule resolution on oxidative stress. Am J Pathol 2016;186:1623-1634.

33. Kim HJ, Kim NC, Wang YD, et al. Mutations in prion-like domains in hnRNPA2B1 and hnRNPA1 cause multisystem proteinopathy and ALS. Nature 2013;495:467-473.

34. Dreveny I, Kondo H, Uchiyama K, Shaw A, Zhang X, Freemont PS. Structural basis of the interaction between the AAA ATPase $\mathrm{p} 97 / \mathrm{VCP}$ and its adaptor protein $\mathrm{p} 47$. EMBO J 2004;23:1030-1039.

35. Schutz AK, Rennella E, Kay LE. Exploiting conformational plasticity in the AAA+ protein VCP/p97 to modify function. Proc Natl Acad Sci USA 2017;114:E6822-E6829.

36. Schuetz AK, Kay LE. A dynamic molecular basis for malfunction in disease mutants of p97/VCP. Elife 2016;5:e20143.

37. Nalbandian A, Llewellyn KJ, Kitazawa M, et al. The homozygote $\operatorname{VCP}(\mathrm{R}(1)(5)(5) \mathrm{H} /$ $\mathrm{R}(1)(5)(5) \mathrm{H})$ mouse model exhibits accelerated human VCP-associated disease pathology. PLoS One 2012;7:e46308.

38. Nalbandian A, Donkervoort $\mathrm{S}, \mathrm{Dec} \mathrm{E}$, et al. The multiple faces of valosin-containing proteinassociated diseases: inclusion body myopathy with Paget's disease of bone, frontotemporal dementia, and amyotrophic lateral sclerosis. J Mol Neurosci 2011;45:522-531. 


\section{Neurology}

\section{Multisystem proteinopathy due to a homozygous p.Arg159His $V C P$ mutation: A tale of the unexpected}

Willem De Ridder, Abdelkrim Azmi, Christoph S. Clemen, et al.

Neurology published online December 17, 2019

DOI 10.1212/WNL.0000000000008763

\section{This information is current as of December 17, 2019}

\section{Updated Information \&} Services

Subspecialty Collections

\section{Permissions \& Licensing}

Reprints including high resolution figures, can be found at: http://n.neurology.org/content/early/2019/12/17/WNL.0000000000008 763.full

This article, along with others on similar topics, appears in the following collection(s):

\section{All Genetics}

http://n.neurology.org/cgi/collection/all_genetics

All Medical/Systemic disease

http://n.neurology.org/cgi/collection/all_medical_systemic_disease Muscle disease

http://n.neurology.org/cgi/collection/muscle_disease

Parkinson's disease/Parkinsonism

http://n.neurology.org/cgi/collection/parkinsons_disease_parkinsonism

Information about reproducing this article in parts (figures,tables) or in its entirety can be found online at:

http://www.neurology.org/about/about_the_journal\#permissions

Information about ordering reprints can be found online:

http://n.neurology.org/subscribers/advertise

Neurology ${ }^{\circledR}$ is the official journal of the American Academy of Neurology. Published continuously since 1951, it is now a weekly with 48 issues per year. Copyright (O 2019 American Academy of Neurology. All rights reserved. Print ISSN: 0028-3878. Online ISSN: 1526-632X.

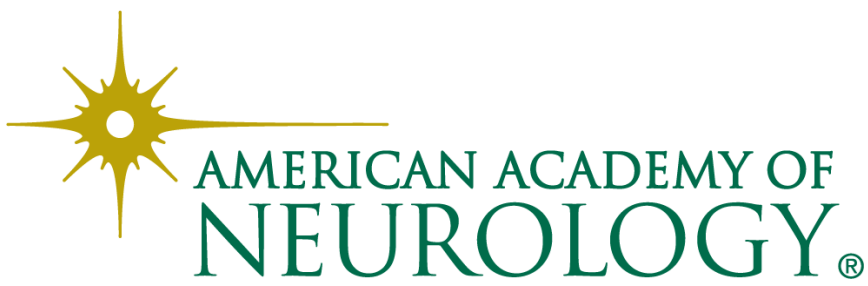

